\title{
Inside the chronic lymphocytic leukemia cell: miRNA and chromosomal aberrations
}

\author{
ANNA GRENDA ${ }^{1,2}$, AGATA A. FILIP ${ }^{1}$ and EWA WĄSIK-SZCZEPANEK ${ }^{3}$ \\ Departments of ${ }^{1}$ Cancer Genetics with Cytogenetic Laboratory, ${ }^{2}$ Pneumonology, Oncology and Allergology and \\ ${ }^{3}$ Haematooncology and Bone Marrow Transplantation, Medical University of Lublin, 20-059 Lublin, Poland
}

Received September 13, 2021; Accepted November 25, 2021

DOI: $10.3892 / \mathrm{mmr} .2022 .12581$

\begin{abstract}
Alterations in microRNA (miRNA/miRs) expression are associated with the occurrence and course of human diseases, including chronic lymphocytic leukemia (CLL). Expression of miRNAs may vary among patients with CLL in different cytogenetic risk groups. The present study assessed the expression levels of the following miRNAs in 35 patients with CLL: hsa-miR-15a, -16-1,-29a,-29c, -34a, -34b,-155,-181a, $-181 b,-221,-222$ and -223 . Fluorescent in situ hybridization (FISH) analysis was performed for 13q14d, 17p13 and 11q22 deletions and chromosome 12 trisomy. Significantly higher expression levels of miR-181a, -221 and -223 were observed in the group at low risk of disease progression (stage 0 ) compared with the group with high risk of CLL progression ( $\mathrm{P}=0.036, \mathrm{P}=0.019$ and $\mathrm{P}=0.038$, respectively). The present study revealed that the expression levels of miRNA-181b and miRNA-223 were significantly higher in the group of patients without $\mathrm{D} 13 \mathrm{~S} 319$ deletion $(\mathrm{P}=0.039$ and $\mathrm{P}=0.037$, respectively). Moreover, the expression levels of miR-15a and miRNA-29c were demonstrated to be significantly higher in the group of patients with CLL who had a tumor protein p53 deletion, identified by FISH, compared with patients without this lesion $(\mathrm{P}=0.047, \mathrm{P}=0.03$ respectively). Based on receiver operating characteristic curve analysis, the present study revealed that miR-181a, -221 and -223 expression was able to distinguish low and high risk of CLL progression in patients. Among the tested miRNAs, miRNA-181a, -221 and -223 were indicated to have the greatest diagnostic potential in CLL.
\end{abstract}

\section{Introduction}

MicroRNAs (miRNAs/miRs) are small, non-coding molecules $\sim 21$ nucleotides long. They have regulatory properties and

Correspondence to: Dr Anna Grenda, Department of Pneumonology, Oncology and Allergology, Medical University of Lublin, 8 Jaczewskiego, 20-059 Lublin, Poland

E-mail: an.grenda@gmail.com

Key words: chronic lymphocytic leukemia, microRNA, chromosomal aberrations control almost all processes in the human body (1). miRNA genes are scattered throughout the genome and they can be located within introns or exons of protein-coding genes (1). Processes involving miRNAs are not fully understood. However, alterations in the expression of individual molecules are associated with the occurrence and course of human diseases. This is particularly evident in cancer $(2,3)$. Research on the miRNA signatures that will most aptly describe the type of tumor and its stage are still being conducted $(2,3)$.

miRNA expression has important diagnostic and prognostic value; therefore, the present study addressed the issue of its alterations in patients with chronic lymphocytic leukemia (CLL). CLL is a hematooncological disease characterized by the accumulation of small, but non-functional mature B cells in peripheral blood, bone marrow, spleen and lymph nodes (4). CLL predominantly affects elderly over the age of 60 years old, but cases of younger patients are currently being observed, even before the age of 50 years old (4). CLL is a heterogeneous disease. There are two main forms, benign and aggressive, but the diagnostic boundary between them is often unclear. Patients with benign CLL may experience transformation of this leukemia to an aggressive form that requires intensive treatment. miRNAs can be used as potential biomarkers in the early diagnosis and precise assessment of benign and aggressive forms of CLL $(4,5)$.

Diagnosticians and clinicians consider numerous clinical and laboratory factors that would indicate the form of leukemia and the risk of disease progression. These include: Rai and Binet staging system, serum markers, zeta-chain-associated protein kinase 70 kinase (ZAP-70) expression, CD38 expression, immunoglobulin variable heavy chain gene $(I g V H)$ and tumor protein p53 (TP53) mutation status, as well as chromosomal aberrations. The latter have a substantial impact on the diagnosis and treatment of CLL. Identification of characteristic, common cytogenetic abnormalities have been considered as a valuable component of the CLL diagnostic panel (4-7).

Deletion of 13q14 is the most frequently observed chromosomal aberration in patients with CLL (5). An isolated $13 q 14$ deletion is a good prognostic factor. Nevertheless, it has been demonstrated that the prognosis is worse when more cells ( $\geq 70 \%)$ with isolated del (13q14) are observed (6). Some genes involved in CLL pathogenesis are located within the 13q14.2-q14.3 region. These include deleted in 
lymphocytic leukemia 2 (DLEU2) with the miRNA-15/16 gene cluster, deleted in lymphocytic leukemia 7 (DLEU7) and retinoblastoma $1(R B 1)(7,8)$.

Deletions of the 11q22-23 region, which harbors the ataxia telangiectasia mutated $(A T M)$ gene locus, are observed in $\sim 20 \%$ of patients (9). In such cases, the disorder is associated with an aggressive course, shorter overall survival (OS), treatment-free survival and rapid progression (10-12). Enlargement of peripheral, abdominal and mediastinal lymph nodes are often observed in patients with 11q deletion $(11,12)$. If the number of lymphocytes with 11q deletion exceeds $25 \%$, the time to therapy is significantly shortened, irrespective of the IgVH mutation status and ZAP-70 and CD38 expression (13).

Chromosome 12 trisomy is the third most common aberration in patients with CLL. It occurs in $15-20 \%$ of patients, and it is an isolated aberration in $>2 / 3$ of patients in this group. The median time to disease progression in such cases is 33 months, while the median OS is 114 months $(11,14)$.

17 p13 deletion is identified in $7 \%$ of patients with CLL and often occurs with the unmutated form of $\operatorname{IgVH}(11,15) .17 \mathrm{p} 13$ deletion involves part of the short arm of chromosome 17, and the most important lost fragment is the $17 \mathrm{p} 13.1$ locus, a site occupied by the TP53 gene. It has been demonstrated that in cases with deletion of a single 17p13.1 allele, TP53 mutations may occur in the second allele (16). This situation is very disadvantageous for the patient, as complete deactivation of the TP53 gene can occur, which is associated with increased treatment resistance (16). Both $17 \mathrm{p} 13$ deletions and TP53 mutations are associated in CLL with rapid disease progression, shortened OS and worse prognosis $(15,16)$. For this reason, identification of these changes is of great importance in clinical management. Their presence in patients' lymphocytes indicates the need for rapid initiation of therapy. TP53-associated disorders also indicate the possibility of developing resistance to chemotherapeutics, which makes treatment difficult $(15,16)$.

Certain miRNA genes associated with leukemogenesis or miRNA-regulated genes (and perhaps still unknown miRNA controller genes) are located in chromosomal regions that are frequently altered in CLL. The miR-15/16 cluster is located on chromosome 13 (locus 13q14.3) between the second and fifth exon of the DLEU2 gene. DLEU2 is located in the minimal deleted region and it does not encode any protein; however, it is necessary for the initiation of miR-15/16 transcription $(17,18)$. Other miRNAs involved in CLL pathogenesis are negative regulators of the $\mathrm{T}$ cell leukemia/lymphoma 1 (TCL1) oncogene: The miR-29 and miR-181 family (19). Pekarsky et al (19) noted low expression of miR-29b and miR-181b in CLL lymphocytes with high level of TCL1 expression. This state is commonly associated with the lack of $I g V H$ mutations and high ZAP70 kinase levels, which indicates a malignant phenotype of CLL.

The miRNA-34 family plays a notable role in CLL pathogenesis. Expression of miRNA-34a is reduced in patients with $17 \mathrm{p}$ deletion or TP53 mutation. Low levels of miR-34a are also observed in patients resistant to fludarabine, even in the absence of $17 \mathrm{p}$ deletions or TP53 mutations (20). Another miRNA from the CLL-associated group is miRNA-155. A high expression level of miRNA-155 observed in patients with CLL can attenuate histone deacetylase 4 and BCL6 transcription repressor expression, leading to the activation of oncogenes associated with increased cell division and apoptosis inhibition (21). Increased expression of miRNA-155 is associated with high levels of ZAP-70 kinase, which corresponds to an aggressive form of CLL (22).

miR-221 and -222 molecules are involved in regulatory mechanisms that maintain CLL lymphocytes in the $\mathrm{G}_{0}$ phase (23). This may be due to the fact that the expression levels of these two miRNAs are inversely correlated with P27 protein expression in both peripheral blood CLL lymphocytes and lymphocytes isolated from bone marrow or lymph nodes. However, differences in the expression of miR-221/222 were found in cells from individual anatomical compartments (peripheral blood, bone marrow, lymph nodes) of the same patients. Higher expression was observed in bone marrow/lymph node lymphocytes compared with peripheral blood cells. However, the correlation with P27 levels was preserved in both cases (23).

Considering this, the aim of the present study was to evaluate miRNA expression associated with chromosomal aberrations in CLL.

\section{Materials and methods}

Studied group. A total of 35 consecutive, treatment-naïve patients with CLL, diagnosed according to standard morphological and immunophenotypic criteria $(24,25)$ were enrolled from October 2012 to December 2013 in the study. Diagnosis was routinely confirmed based on peripheral blood smear analysis by an independent pathologist. The study group consisted of $15(43 \%)$ women and $20(57 \%)$ men. The median age was 63 years ( $\mathrm{SD}=8.19$; min-max, 46-84 years). According to the Rai classification (26), 12 (34\%) patients were in stage $0,10(29 \%)$ in stage I, eight (23\%) in stage II, two (6\%) in stage III and three (8\%) patients were in stage IV. There were $12(34 \%)$ patients in the low risk group (Rai stage 0), 18 (52\%) patients in the intermediate risk group (Rai stage I and II) and the high risk group (Rai stage III) included five (14\%) patients. Clinical and pathological features of the studied group are presented in Table I. White blood cell count, lymphocytosis, $\beta 2$ microglobulin, lactate dehydrogenase and the percentage of ZAP-70- and CD38-positive cells were assessed according to standard protocols at the Clinic of Hematooncology and Bone Marrow Transplantation (Lublin, Poland) $(24,25)$. Written informed consent was obtained from patients at the time of taking the blood for the study. The present study was conducted with the approval of the Ethics Committee of the Medical University of Lublin (approval no. KE-0254/155/2010).

Collection and culture of lymphocytes for cytogenetic tests. Fresh peripheral blood samples were collected into lithium heparin (as an anticoagulant) tubes and placed in a $37^{\circ} \mathrm{C}$ incubator for 1-2 $\mathrm{h}$ to sediment erythrocytes and platelets. After sedimentation, the fraction above the sediment containing white blood cells was collected and the obtained cells were used for cell cultures.

Lymphocyte suspension cultures were carried out in duplicate, in a volume of $15 \mathrm{ml}$ of medium in sterile Falcon culture flasks (Sarstedt, Inc.) at $37^{\circ} \mathrm{C}$ (Haereus Incubator; Heraeus Holding $\mathrm{GmbH}$ ). The culture medium was RPMI 


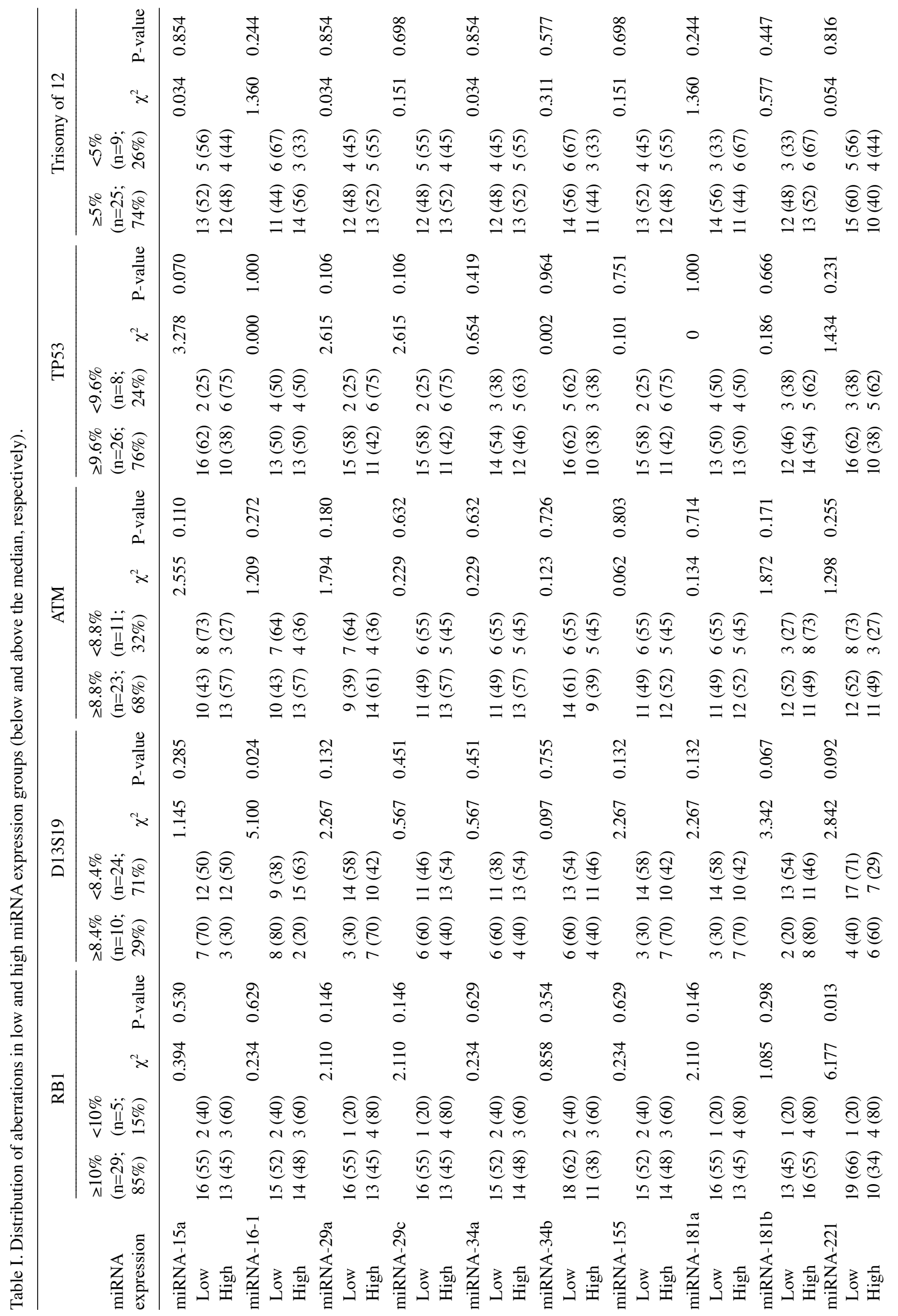




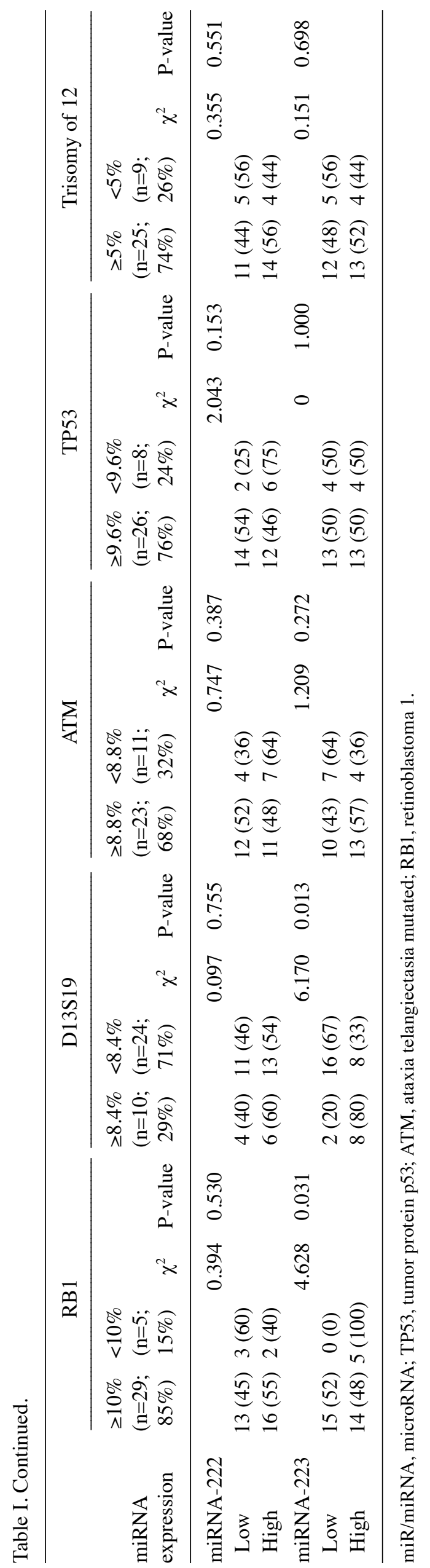

1640 with L-glutamine (Biomed Lublin S.A.) supplemented with $15 \%$ heat-inactivated fetal bovine serum and $1 \%$ mixture of antibiotics and antimycotics (Gibco; Thermo Fisher Scientific, Inc.).

The cultures were run for 5 days with daily agitation by gentle shaking. On the last day of culture, KaryoMAX ${ }^{\mathrm{TM}}$ Colcemid $^{\mathrm{TM}}$ (Gibco; Thermo Fisher Scientific, Inc.) was added to each culture to a final concentration of $0.1 \mu \mathrm{g} / \mathrm{ml}$. Immediately after the addition of Colcemid, the cultures were incubated for $1-1.5 \mathrm{~h}$ at $37^{\circ} \mathrm{C}$ to stop cell divisions at the metaphase stage. The cultures were then placed into $15 \mathrm{ml}$ tubes and centrifuged at $80 \mathrm{xg}$ for $10 \mathrm{~min}$ at room temperature. Subsequently, the supernatant was collected and $\sim 10 \mathrm{ml}$ of $0.075 \mathrm{M} \mathrm{KCl}$ (POCH; Avantor, Inc.) at $37^{\circ} \mathrm{C}$ was added dropwise to the cell pellet and incubated at $37^{\circ} \mathrm{C}$ for $15-20 \mathrm{~min}$. After incubation, the suspensions were centrifuged at $80 \mathrm{x}$ g for $10 \mathrm{~min}$ at room temperature. After centrifugation, the supernatant was collected and the cell pellet in the metaphase stage was immediately fixed in a 1:3 solution of glacial acetic acid and methanol (both Sigma-Aldrich; Merck $\mathrm{KGaA}$ ) at $-20^{\circ} \mathrm{C}$. The fixative was added in the volume of $\sim 10 \mathrm{ml}$, and the suspensions were shaken briefly and immediately they were centrifuged at $80 \mathrm{x} \mathrm{g}$ for $10 \mathrm{~min}$ at room temperature. The fixation step was repeated three times. After the last rinse, the fixative was added and the opalescent lymphocyte suspension was delivered in the fixative. Drops of this material were spread on the dry microscope slide super frost plus (Thermo Scientific, Inc.) and dried. Metaphase spreads were checked using an eclipse Ni-U Nikon upright light microscope (Nikon Corporation) at a magnification of $\mathrm{x} 200$ and using a Nikon Plan Fluor lens 20x0.50.

Fluorescent in situ hybridization (FISH). FISH was carried out to analyze the most common chromosomal aberrations using specific fluorescently labeled cytogenetic probes. They included: i) 13q14 Deletion, miR-15/16 gene locus, Vysis D13S319 probe and RB1 Vysis LSI 13 (RB1) probe (Abbott Molecular); ii) 17p13 deletion, Vysis LSI TP53 probe (Abbott Laboratories); iii) 11q22-23 deletion, Vysis LSI ATM probe (Abbott Laboratories); and iv) trisomy 12, Vysis CEP 12 probe (Abbott Laboratories).

Dried slides with spattered drops of CLL suspension were incubated in $70 \%$ formamide at $73^{\circ} \mathrm{C}$ for $5 \mathrm{~min}$. Next, the slides were dehydrated in a series of ethyl alcohol dilutions (70, 80 and 96\%), each for 2 min and then dried at room temperature. Subsequently, the slides with fluorescent probes were incubated in the dark at $73^{\circ} \mathrm{C}$ for $5 \mathrm{~min}$ to denature and then covered with a coverslip. Fixogum-protected slides were incubated in a humidity chamber at $37^{\circ} \mathrm{C}$ for $20 \mathrm{~h}$. After this, the preparations were washed in a solution of $0.4 \mathrm{X}$ saline-sodium citrate buffer (SSC)/0.3\% NP-40 (non-ionic detergent) (Abbott Laboratories) at $73^{\circ} \mathrm{C}$ for $2 \mathrm{~min}$, followed by $2 \mathrm{X} \mathrm{SSC} / 0.1 \%$ NP-40 incubation at room temperature for $1 \mathrm{~min}$. Next, the slides were dehydrated in a dilution series of ethyl alcohol (70, 80 and 96\%) for 2 min each and air-dried in the dark. Next, $10 \mu \mathrm{l}$ of DAPI was applied and coverslips were put on the slides. Slides were analyzed at 1,000x magnification under immersion (100x1.45 Plan Apo $\lambda$ Oil lens; Nikon Corporation), using an eclipse Ni-U Nikon upright fluorescent 
microscope (Nikon Corporation) with a UV lamp. At least 100 nuclei (or metaphases) were analyzed per sample, and the percentage of aberrant nuclei/metaphases was calculated.

Acquisition and storage of peripheral blood lymphocytes for molecular studies. Fresh peripheral blood samples $(4.5 \mathrm{ml})$ from patients with CLL were collected into EDTA tubes and were diluted $1: 1$ with PBS without $\mathrm{Ca}^{2+}$ and $\mathrm{Mg}^{2+}$ (Biomed Lublin S.A.). The prepared blood was layered on Lymphoprep $^{\mathrm{TM}}$ (STEMCELL $^{\mathrm{TM}}$ Technologies) and centrifuged in a density gradient (11). The samples were centrifuged immediately after layering at $560 \mathrm{x}$ g for $30 \mathrm{~min}$ at room temperature in $15 \mathrm{ml}$ conical tubes. Leukocyte interphases were collected after centrifugation, using a truncated needle and transferred to a $50 \mathrm{ml}$ conical tube.

Leukocytes were washed three times with $45 \mathrm{ml}$ of PBS, followed by centrifugation at $560 \mathrm{x}$ g for $10 \mathrm{~min}$ at room temperature. The supernatant was removed after each centrifugation. After the second wash, the cells were counted in a Thom chamber using Túrk's fluid (Chempur). The total number of lymphocytes were determined in a given collected amount of blood. Subsequently, the lymphocytes were divided into $1.5 \mathrm{ml}$ Eppendorf tubes, with no more than $1 \times 10^{7}$ cells per tube. Lymphocyte suspensions were centrifuged at $560 \mathrm{x} \mathrm{g}$ for $10 \mathrm{~min}$ at room temperature, and then the supernatant was removed to obtain a dry cell pellet. Cells were stored at $-80^{\circ} \mathrm{C}$ until RNA isolation.

Measuring miRNA expression. The miRNeasy Mini kit (Qiagen, Inc.; cat. no. 217084) was used to isolate RNA with miRNA fraction from the cells according to the manufacturer's instructions. The quality of isolated RNA was assessed using a NanoDrop 2000 (Thermo Fisher Scientific, Inc.). RNA was stored at $-80^{\circ} \mathrm{C}$ until further analysis.

Reverse transcription was conducted to obtain complementary (c)DNA for real-time PCR using the Universal cDNA Synthesis kit (Exiqon; Qiagen, Inc.) according to the manufacturer's instructions. The reaction mixture $(20 \mu \mathrm{l})$ contained $4 \mu \mathrm{l}$ of reaction buffer, $9 \mu \mathrm{l}$ of nuclease-free water, $2 \mu \mathrm{l}$ of enzyme mix, $1 \mu 1$ ( $0.15 \mathrm{fmol})$ of 'spike in' and $4 \mu 1$ of RNA $(5 \mathrm{ng} / \mu \mathrm{l})$. Reverse transcription was carried out in an Applied Biosystems 2720 thermal cycler (Applied Biosystems; Thermo Fisher Scientific, Inc.). Reaction conditions were as follows: $42^{\circ} \mathrm{C}$ For $60 \mathrm{~min}, 95^{\circ} \mathrm{C}$ for $5 \mathrm{~min}$ and direct cooling to $4^{\circ} \mathrm{C}$. The cDNA samples were stored at $-20^{\circ} \mathrm{C}$ until real-time PCR was performed. Real-time PCR reaction was performed using the SYBR ${ }^{\circledR}$ Green Master Mix kit (Exicon). Real-time PCR reactions were performed using specific primers (miRCURY LNA $^{\mathrm{TM}}$ Universal RT PCR miRNA LNA ${ }^{\mathrm{TM}}$ PCR primer set; cat. no. 339306; Exicon; Qiagen, Inc.) for: Hsa-miR-15a, $-16-1,-29 a,-29 c,-34 a,-34 b,-155,-181 a,-181 b,-221,-222$ and -223. U6 RNA (U6 snRNA PCR primer set; UniRT, Exiqon, cat. no. 203907) was used as an internal control.

Real-time PCR reaction mix (10 $\mu \mathrm{l})$ contained $5 \mu \mathrm{l} \mathrm{SYBR}$ Green master mix, $4 \mu 1$ of cDNA diluted $\mathrm{x} 80$ with nuclease-free water and $1 \mu \mathrm{l}$ of appropriate specific primers. Real-time PCR reaction was carried out using an Applied Biosystems 7500 Fast Real-Time PCR System (Applied Biosystems; Thermo Fisher Scientific, Inc.). Conditions for real-time PCR were in accordance with the protocol included in the $\mathrm{SYBR}^{\circledR}$ Green master mix kit (Exiqon; Qiagen, Inc.). The initial step was denaturation at $95^{\circ} \mathrm{C}$ for $10 \mathrm{~min}$, followed by 40 amplification cycles with the following temperature profile: $95^{\circ} \mathrm{C}$ For $10 \mathrm{sec}$ and $60^{\circ} \mathrm{C}$ for $1 \mathrm{~min}$. Each reaction was run in duplicate and was controlled by a melting curve. The threshold cycle was obtained from the logarithmic growth phase of the product from samples from patients with CLL. Evaluation of miRNA expression was conducted using the $2^{-\Delta \Delta C \mathrm{C}}$ method (27).

Statistical analysis. U-Mann-Whitney test was used to compare miRNA expression in individual patient groups. The data are presented as median and interquartile range. The Spearman rank test was used to estimate the correlation between the data on a continuous scale. The $\chi^{2}$ and Fisher's exact tests were used to compare individual groups of patients with respect to clinical and demographic characteristics. Statistical analysis was performed using the Statistica 12 software (TIBCO Software Inc.). $\mathrm{P}<0.05$ was considered to indicate a statistically significant difference.

\section{Results}

Chromosomal aberrations. Identification of chromosomal aberrations using the FISH method was performed in 34 (97\%) of the 35 patients enrolled in the study. In one patient, blood was collected for EDTA only, and therefore no blood was available for lithium heparin for culture and FISH. Cytogenetic aberrations were observed in 30 patients $(88 \%)$. Normal karyotype was found in four patients (12\%). Single chromosomal changes were found in 12 patients (35\%), two different aberrations occurred in 12 patients $(35 \%)$ and $\geq 3$ changes were identified in six patients (18\%; data not shown). The most common aberration observed was 13q14 (D13S319) deletion $(\mathrm{n}=23 ; 68 \%) .11 \mathrm{q} 22-23$ deletion $(\mathrm{n}=11 ; 32 \%)$ was the second most common in the studied group of patients. The third most common was trisomy of chromosome $12(n=9 ; 26 \%)$. A total of eight patients (24\%) had a $17 \mathrm{p} 13$ deletion, and five patients (15\%) had a deletion of the 13q14 region where the $R B 1$ gene is located. Notably, in three cases (9\%) it coexisted with D13S319 deletion, and in two cases there was no D13S319 deletion. The distribution of the occurrence of individual chromosomal aberrations depending on the cut-off thresholds is presented in Table I.

Expression of miRNA and disease risk progression according to the Rai staging. The present study observed significantly higher expression levels of miR-181a, -221 and -223 in the group with low risk of disease progression (stage 0) compared with the high risk of CLL progression $(\mathrm{P}=0.036, \mathrm{P}=0.019$ and $\mathrm{P}=0.038$, respectively; Fig. 1D-F). Markedly higher expression levels of miR-34a, -181a and -181b were observed in the group with low risk of disease progression compared with the intermediate-risk progression group, but it was not statistically significant (Fig. 1A-C).

Expression of miRNA and chromosomal aberrations. The present study revealed that miR-181b and -223 expression levels were significantly higher in the group of patients without $D 13 S 319$ deletion $(\mathrm{P}=0.039$ and $\mathrm{P}=0.037$, respectively; Fig. $1 \mathrm{~J}$ and $\mathrm{K}$ ). Higher miR-16-1 expression was observed in the 

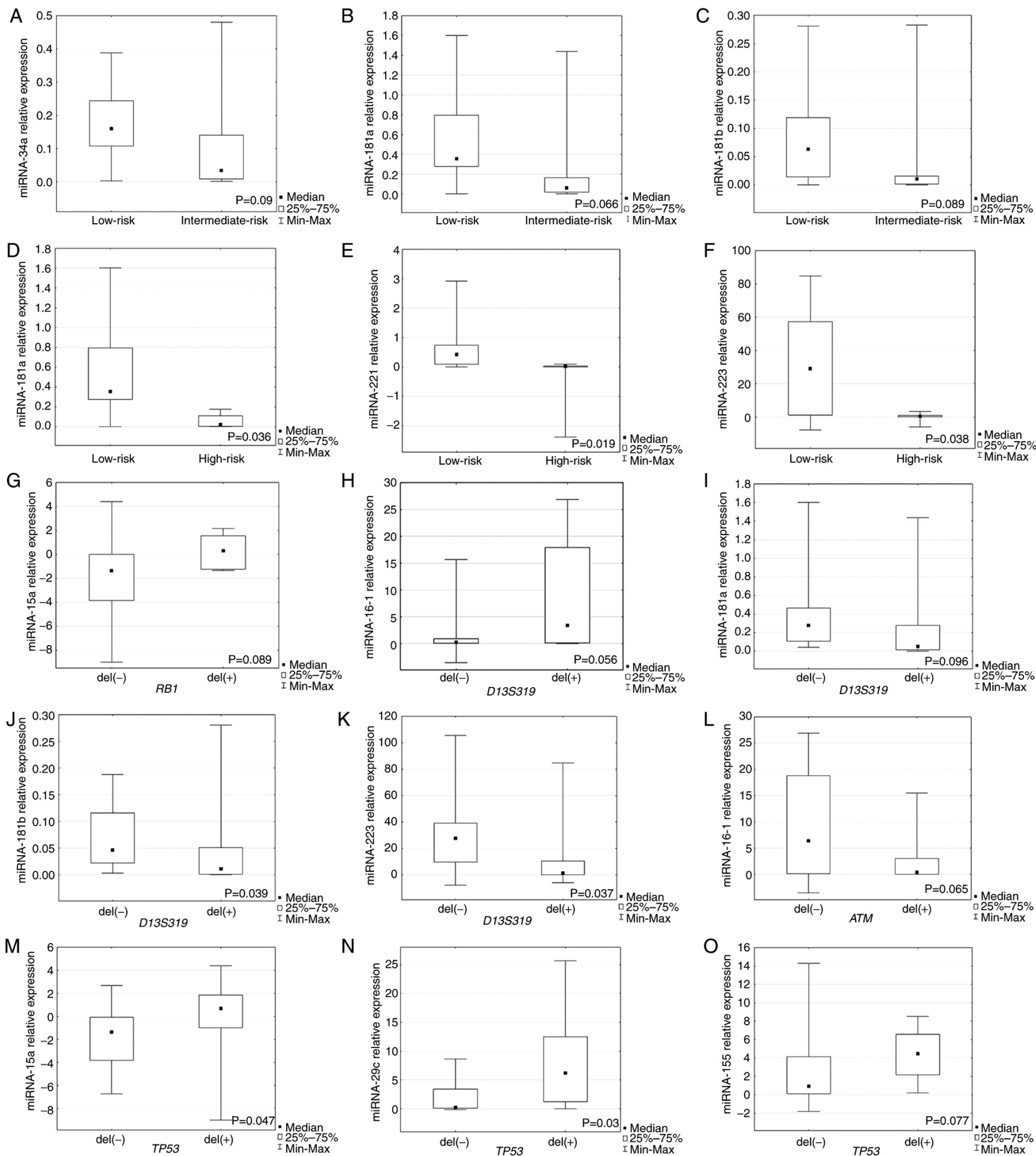

Figure 1. Expression of miRNAs in individual groups of patients with chronic lymphocytic leukemia. Relative expression of (A) miR-34a, (B) miR-181a and (C) miR-181b in low- and intermediate-risk groups. Relative expression of (D) miR-181a, (E) miR-221 and (F) miR-223 in low- and high-risk groups. (G) Relative expression of miR-15a in group of patients with or without deletions in RB1 locus. Relative expression of (H) miR-16-1, (I) miR-181a, (J) miR-181b and (K) miR-223 in patients with or without deletions in D13S319 locus. (L) Relative expression of miR-16-1 in patients with or without deletions in ATM locus. Relative expression of (M) miR-16-1, (N) miR-15a, miR-29c and (O) miR-155 in patients with or without deletions in TP-53 locus. miRNA, microRNA; RB1, retinoblastoma 1; ATM, ataxia telangiectasia mutated; TP53, tumor protein 53.

group with $D 13 S 319$ deletion (Fig. 1H), but it was not statistically significant. Non-significant lower expression of miR-181a was detected in patients with D13S319 deletion (Fig. 1I).

For $R B 1$ deletion identified by FISH, a higher expression of miRNA-15a was observed in the group of patients with deletion of this locus, but it was not statistically significant (Fig. 1G). Moreover, the expression levels of miR-15a and miR-29c were significantly higher in the group with TP53 deletion identified by FISH compared with the group without this deletion $(\mathrm{P}=0.047, \mathrm{P}=0.03$, respectively; Fig. $1 \mathrm{M}$ and $\mathrm{N})$. 

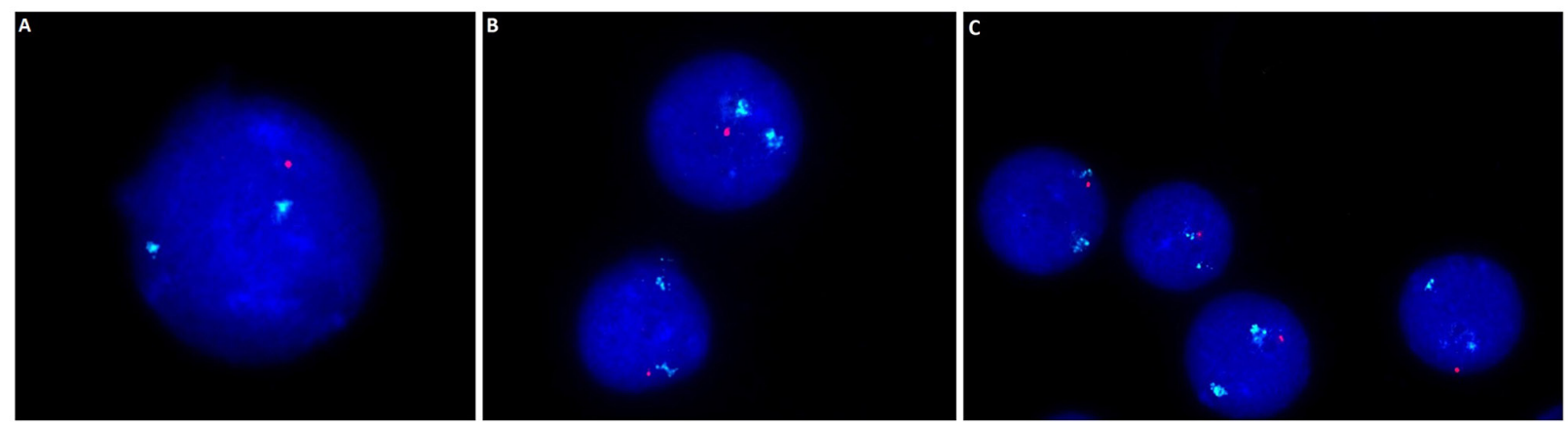

Figure 2. Example images showing the 17q13 deletion within which the TP-53 gene is located. (A), (B) and (C): DAPI-stained nuclei in which a monoallelic deletion of the region where the $T P-53$ gene is located is visible (red) and centromere 17 as a control (green).

A

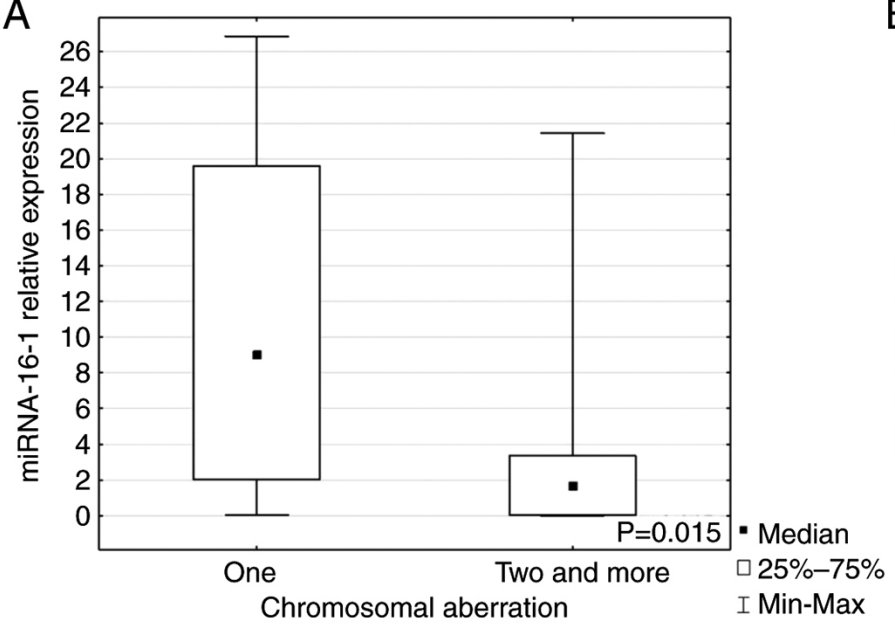

B

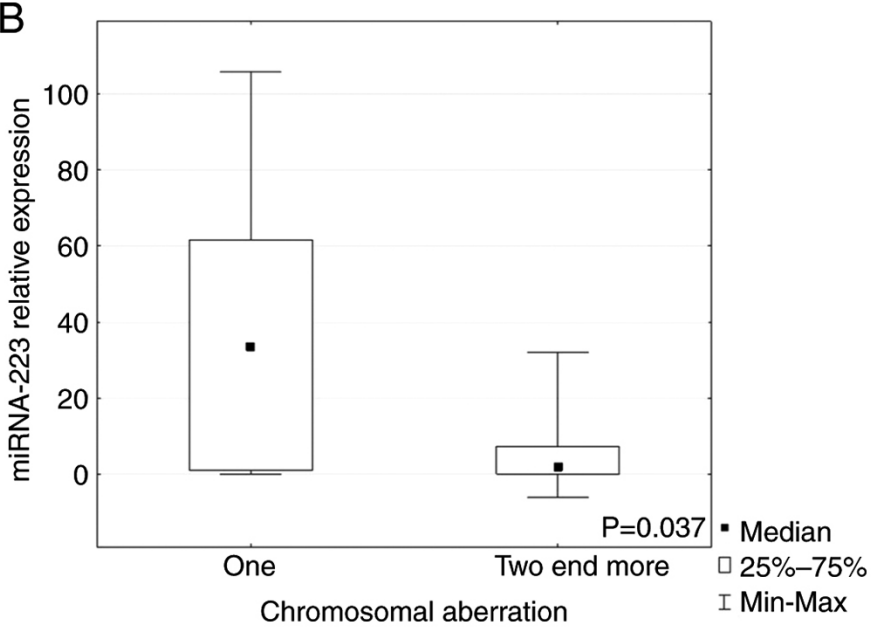

Figure 3. Expression of miRNA-16-1 and miRNA-223 in the group of patients with chromosomal aberrations. Relative expression levels of (A) miRNA-16-1 and (B) miR-223 in patients with one or $\geq 2$ chromosomal aberrations. miRNA, microRNA.

Higher miR-155 expression was detected in the group of patients with TP53 deletion, but this was not significant (Fig. 1O). Example images presenting the 17q13 deletion within which the TP-53 gene is located are presented in Fig. 2. A non-significantly lower expression of miR-16-1 was found in the group of patients with CLL with ATM deletion compared with patients without this deletion (Fig. 1L).

When the patients were divided into groups with one or $\geq 2$ chromosomal aberrations, it was demonstrated that miR-16-1 and miR-223 expression levels were significantly higher in the group with just one aberration compared with groups with $\geq 2$ lesions $(\mathrm{P}=0.015, \mathrm{P}=0.037$, respectively; Fig. 3A and B). Expression of each miRNA marked as a low or high in the group with a given aberration are presented in Table I.

Expression of miRNAs depending on clinical and demographical factors. It was observed that in the patient group with low miR-34b expression, the percentage of cells expressing ZAP-70 over $20 \%$ was non-significantly more frequent compared with patients with high expression of this molecule $(\mathrm{P}=0.065$; Table II $)$.

Diagnostic value of miRNA expression in differentiating low and high risk of CLL progression. In further analyses, the utility of miRNA expression was evaluated as a diagnostic factor. Receiver operating characteristic curves (ROC) were generated and areas under the curves (AUC) were defined. It was revealed that miR-181a, -221 and -223 expression had the ability to distinguish between low and high risk of progression in patients with CLL (Fig. 4A-C). Sensitivity for miR-181a was $69 \%$ and specificity was $100 \%$ (AUC $=0.875 ; 95 \%$ CI, 0.687-1; $\mathrm{P}=0.0001$; Fig. 4A). Sensitivity for miR-221 was $78 \%$ and specificity was $91 \%$ (AUC $=0.889 ; 95 \%$ CI, $0.713-1 ; \mathrm{P}=0.00001$; Fig. 4B). Sensitivity for miR-223 was $72 \%$ and specificity was $100 \%$ (AUC $=0.836 ; 95 \%$ CI, 0.634-1; P=0.0011; Fig. 4C).

\section{Discussion}

According to the prospective observational study by Mato et al (27) covering almost 1,500 patients with CLL stratified by the results of cytogenetic/fluorescence in situ hybridization testing, three risk levels could be distinguished: Unfavorable [presence of $\operatorname{del}(17 p)$ or $\operatorname{del}(11 q)]$, favorable [absence of del(17p) and del(11q)] and unknown. FISH testing was performed in $58 \%$ of patients, cytogenetic testing was performed in 861 patients (58\%) at enrollment and only $40 \%$ of these patients were re-tested before starting the subsequent line of therapy. FISH testing is rarely performed, and patients with unfavorable risk genetics treated with immunochemotherapy 


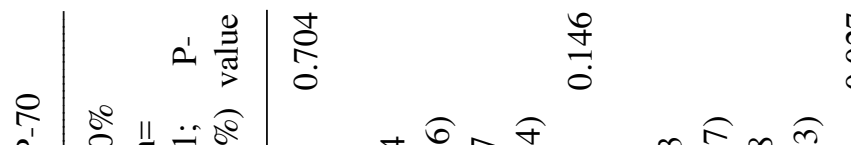

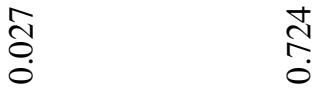

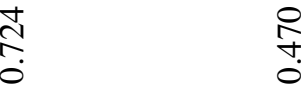

究

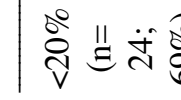

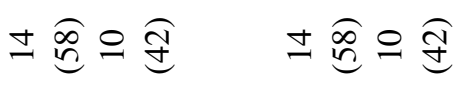

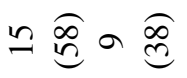

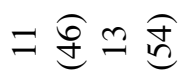

$\because$ 点 $=\stackrel{0}{+}$

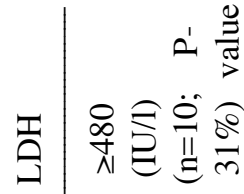

$-$

$\ln \left(\frac{10}{20}\right.$

-

$\frac{\pi}{0}$

京官

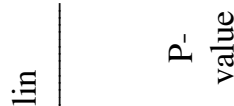

毒范

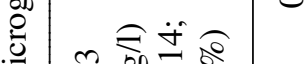

$n$ हृ $n$ हृ

n

+ 导 $\circ$ \&

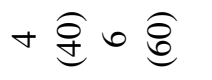

+ 导 $\circ$ \&

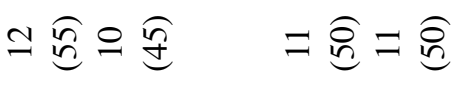

웜

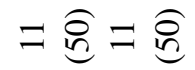

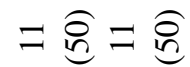

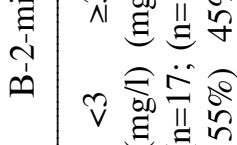

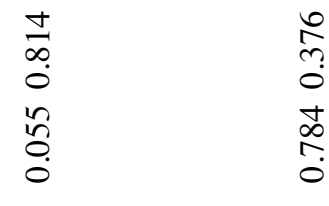

尚

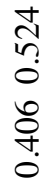

$\infty \underset{\hat{n}}{\overparen{f}}$

$\infty$ हิ

in

$\stackrel{\infty}{\circ}$

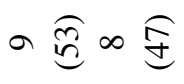

워응

$\infty \underset{\text { 里 }}{\widehat{\approx}}$

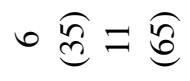

oे

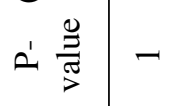

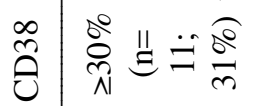

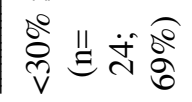

离

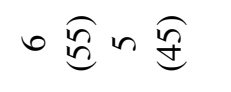

字

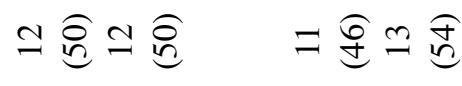

孚的

$+\underset{d}{\text { d }}$

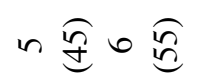

矮 6 尔

$\cong$ 恖 $=\stackrel{0}{+}$

$\simeq \widehat{尺} \simeq \stackrel{\circ}{6}$

윰ำ

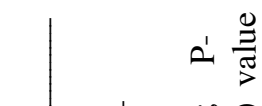

$n$
$\infty$
0

$\bar{\infty}$
$\vdots$
0

$m$ \&ิ월

กั

ำ

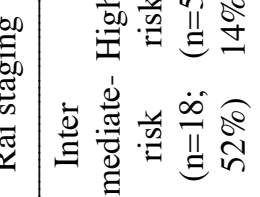

$\infty$ 导을

n

워 $n$

芩

$+\sqrt{\mathfrak{c}}-\sqrt{\mathfrak{d}}$

$-\sqrt[a]{d}+\stackrel{a}{c}$

窇.

的

aहै

の हैم

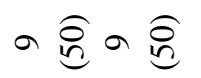

$=\widehat{\vec{b}}-\widehat{\vec{d}}$

n 犬ิ

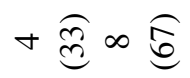

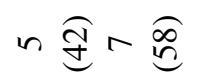

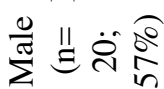

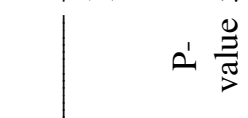

$\stackrel{\infty}{\infty}$

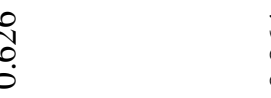

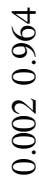

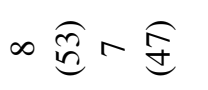

$\infty \underset{\tilde{n}}{\widehat{a}}$ 导

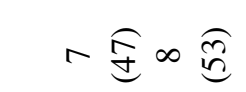

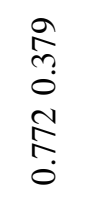

$\stackrel{\infty}{4}$

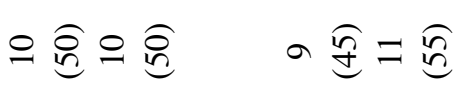

을을

○ 导 $a$ \&

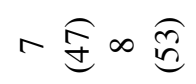

$\begin{array}{lll}0 & \\ \substack{\infty \\ 0} & -\end{array}$

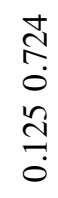

$\infty$ 导 $\sigma$ ह

-

- $\underset{\mathrm{y}}{\widehat{\hat{n}}}$

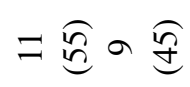

융요

\section{。}

- 在응

० $\sqrt[n]{n}=\sqrt{6}$

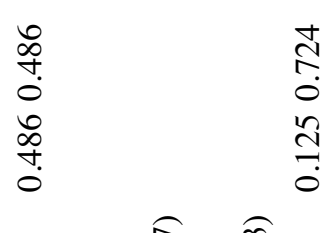

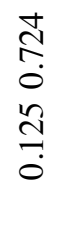

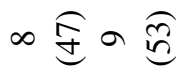

욜 $=\sqrt{6}$

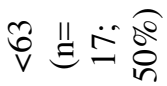

。

- 存으용

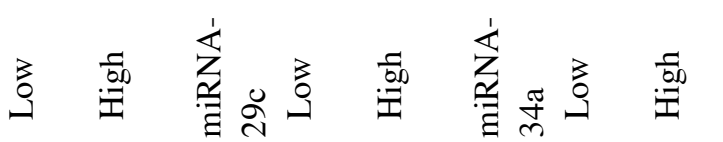




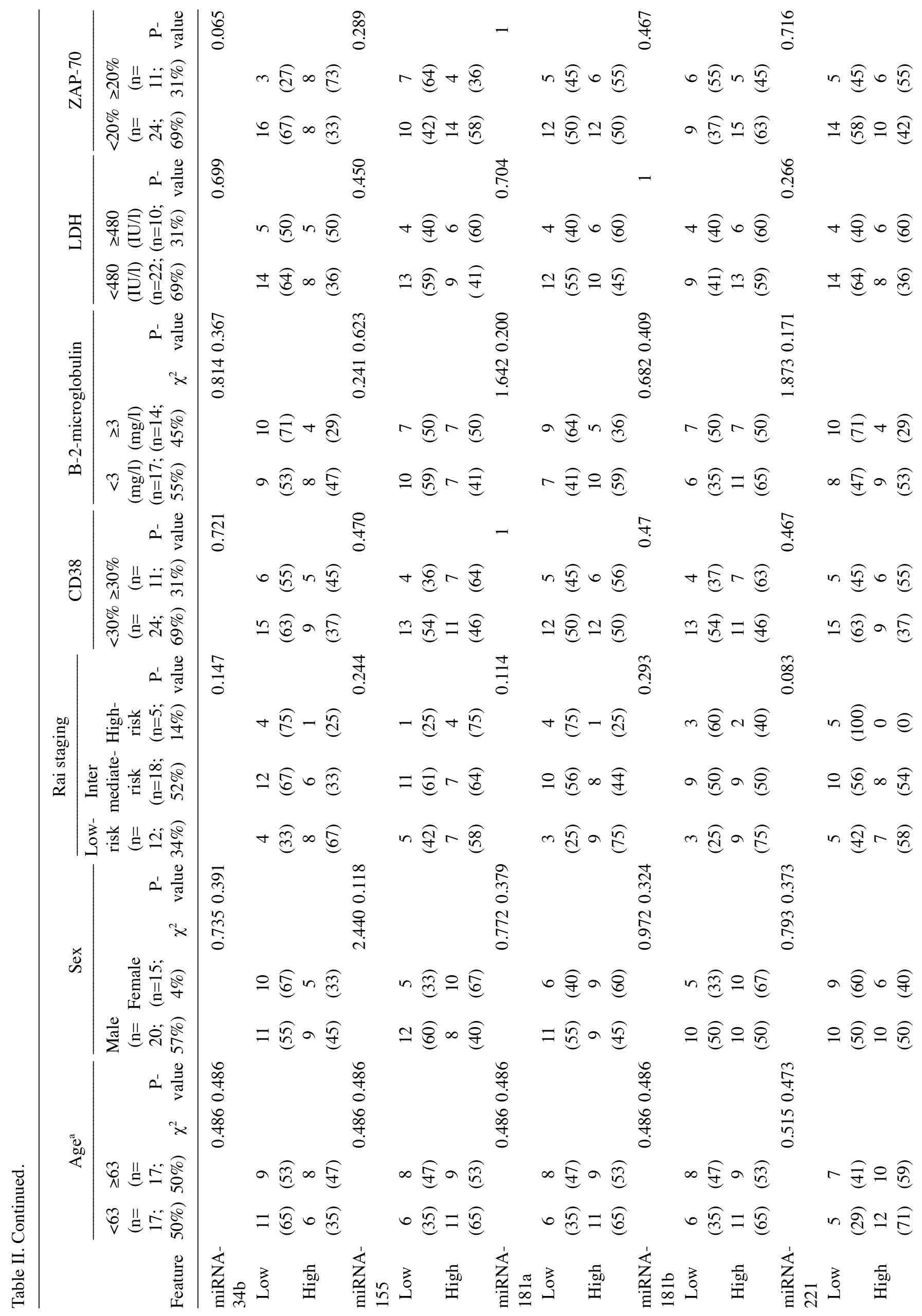




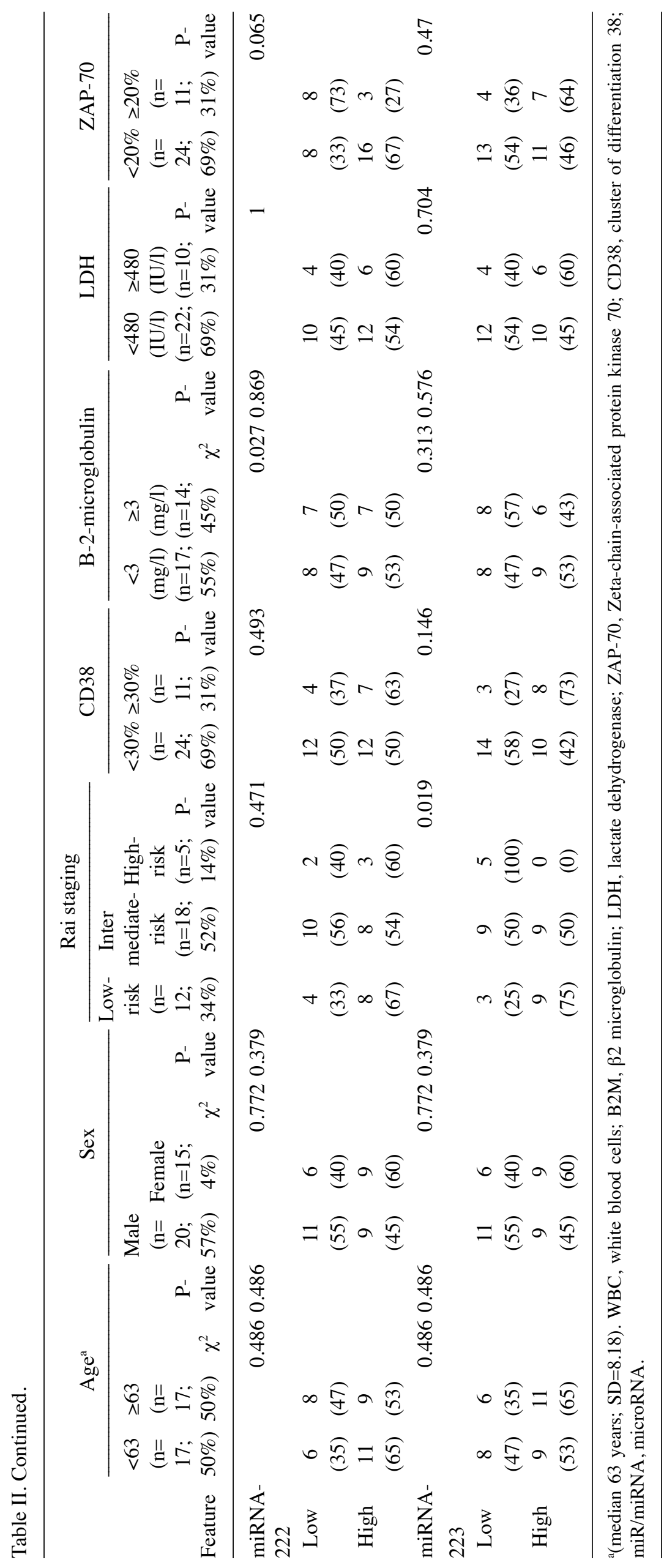



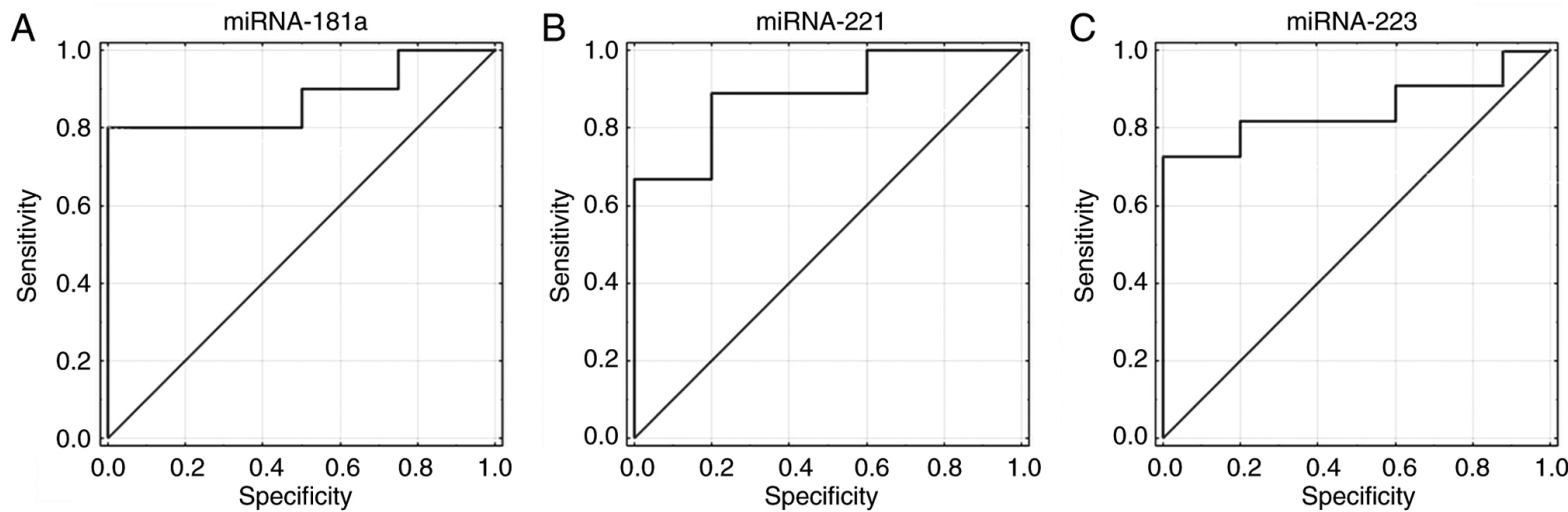

Figure 4. ROC curves plotted to examine diagnostic utility of miRNAs. (A) miRNA-181a, (B) miRNA-221 and (C) miRNA-223 were examined using ROC curves to indicate the sensitivity and specificity of each miRNA in diagnosing chronic lymphocytic leukemia. ROC, receiver operating characteristic curves; miRNA, microRNA.

combinations have worse outcomes (27). However, Hallek et al (28) stated in the International Workshop on CLL guidelines for diagnosis, indications for treatment, response assessment and supportive management of CLL that FISH is not essential to diagnose CLL, but can help predict prognosis or assess tumor burden $(28,29)$. In addition, they pointed that the indication for treatment did not depend on the results of these tests, but on the clinical stage and symptoms of the patient (28).

Baliakas et al (30) reported that a complex karyotype, defined as the presence of $\geq 3$ numerical and/or structural chromosomal aberrations detected with the use of chromosome-banding analysis, should not be indisputably considered unfavorable in CLL due to the fact that it represents a heterogeneous group with variable clinical behavior. Furthermore, the coexistence of $\geq 5$ chromosomal aberrations seems to be unfavorable prognostically, regardless of clinical stage or TP53 status, while the occurrence of $<5$ cytogenetic changes is clinically relevant only when coexisting with TP53 disruption (30). Simultaneously, Baliakas et al (30) indicated that a complex karyotype in CLL is not always adverse and demonstrated that additional chromosome 12 and 19 can be involved in prolonging OS compared with patients with and without a complex karyotype.

The present study observed $>2$ aberrations in $35 \%$ of patients and $>3$ in six patients with CLL. Moreover, miR-16-1 and miR-223 expression levels were revealed to be significantly higher in patients with just one aberration compared with patients with $\geq 2$ aberrations. This could indicate that in patients with CLL, the genome with more complexed karyotype is more disrupted, which may be reflected in genetic changes (aberrations, mutations), but also in epigenetic changes (methylation, miRNA expression). miRNA-16-1 and miRNA-223 are considered as tumor suppressors and, along with pathological changes in the genome, their expression levels are reduced as a result of deletion of their genes or mutation in the 3'UTR regions of oncogenic target genes; this prevents efficient binding of mRNAs and subsequent silencing, especially in the seed region (the best matching sequence) (31-33). A significant destabilization of the genome is observed in tumor cells, including leukemia cells, which may be associated with reduced survival time, worse prognosis and ineffective therapy. Chromosomal aberrations may be accompanied by mutations and epigenetic disorders. Understanding auxiliary markers such as miRNAs as epigenetic regulators may be helpful in patient stratification and qualification for personalized treatment, and thus it seems to be the right research direction. However, difficulties are often encountered in the interpretation of study results (6,31-33).

An example is the presence of the D13S319 deletion, a region containing miRNA15a/16 genes. Research has demonstrated that patients with the loss of this region had a favorable prognosis (6). 13q14 deletion may also appear as a coexisting lesion, and it has been confirmed that the prognosis for patients is improved in the case of an isolated deletion (6). Reports have demonstrated that there is a relationship between low levels of miR-15/16 and 13q14 deletion; notably, when $>70-80 \%$ of cells carry $13 q 14$ deletion, then it is most often biallelic $(18,34)$. Such a relationship was not revealed in the present study. The lack of correlation between the expression of miR-15/16 and del13q14 in the present study may be due to the fact that only two patients in the study group had $>70 \%$ of cells with a deletion of the region (data not shown) where miRNA genes were located. Nevertheless, there were also reports, for example by Rossi et al (35) that indicate that there is no relationship or correlation between 13q14 deletion and miR-15/16 expression. Nonetheless, the present study revealed that patients with D13S319 deletion had lower expression of miRNA-181b and miRNA-223. In addition, it should be mentioned that $70 \%$ $(\mathrm{n}=16)$ of patients with the D13S319 deletion had an additional aberration. Due to the fact that D13S319 deletion itself may be a useful prognostic factor, additional chromosome aberrations may indicate a more aggressive course of CLL and the appearance of abnormal miRNA expression may be the evidence of this.

miR-181 is considered a regulator of TCL1, and the product of this gene is involved in the aggressive form of CLL (36-38). Moreover, miR-181b expression is often decreased in patients with progressive CLL disease. Therefore, higher expression of this miRNA in patients without D13S319 lesions appears to be a good complementary marker indicating a potentially improved prognosis. Especially since the decrease in its expression is observed with CLL progression, which also qualifies this molecule as a potential disease monitoring factor $(35,36)$. 
Similarly, miRNA-223 expression decreases as the disease progresses (37). Zhou et al (39) reported that lower expression of this miRNA can be observed with the transition of CLL from stage $\mathrm{A}$ to $\mathrm{C}$, according to the Binet classification, and the transformation of a low-risk form (stage 0 according to the Rai classification) into a high-risk form of CLL progression (stage III and IV according to the Rai classification). Low expression of miR-223 may indicate a worse prognosis and, additionally, it is frequently observed in patients with non-mutated $\operatorname{IgVH}(39)$. Thus, similarly to miR-181, high miR-223 expression may be a useful prognostic factor with the simultaneous presence of D13S319 deletion and coexisting aberrations.

In the present study, higher expression levels of miRNA-15a and miRNA-29c were also observed in the group of patients with $T P-53$ deletion. There is evidence that tumor protein 53 can stimulate miRNA-15a expression (40). By contrast, $m i R-15 a$ (and miR-16-1) may be involved in TP53 silencing at the posttranscriptional level, directly targeting its 3'-UTR region, and miRNA-15a overexpression may result in reduced TP53 expression at the RNA and protein levels (41). Liu et al (42) demonstrated that miR-15a and miR-16-1 expression levels were significantly decreased in CLL cells with TP-53 loss. Janaki et al (43) reported that miRNA-15a and TP-53 form a specific feedback loop: TP-53 regulates miRNA by stimulating its expression, and miRNA-15a has the ability to silence $T P-53$ expression. In the present study, high expression of miRNA-15a in the group with TP-53 deletion was notable. Perhaps the detection of an inverse correlation between these parameters was influenced by the small size of the group, which included only eight cases with $T P-53$ deletion. In addition, other regulatory mechanisms could affect miRNA-15a expression, with decreased TP-53 expression as a result of deletion. This topic remains to be considered as a further, extended research in terms of methodology and in terms of group size.

When miR-29c expression was analyzed, it was found that it was higher in the presence of $17 \mathrm{p} 13$ deletion compared with lymphocytes from patients without this change in the present study. Pekarsky et al $(19,44)$ indicated that higher miR-29 expression may characterize the initial stage of CLL, while its reduction can indicate disease progression and its transformation into an aggressive form. In the present study, this thesis was not confirmed because higher expression was recorded in the presence of $17 \mathrm{p} 13$ deletion, which is considered a negative prognostic factor indicating an aggressive form of CLL or the risk of transformation of the benign to aggressive form. Mraz et al (45) revealed that miR-29c expression was reduced in the presence of TP53 deletion or mutation. The different results of the present study may have been influenced by the size of the groups being compared (patients without deletion $=26$; patients with deletion=8) as in the miRNA-15a study. Particular attention should be paid to this issue in further studies, due to the fact that no associations were found between miR-34 (miR-34a, miR-34b) and TP-53 in the current study, and in the literature there are examples of the relationship between these molecules in CLL (46)

Zenz et al (20) and Mraz et al (45) reported a relationship between the occurrence of TP-53 deletions/mutations and reduced miR-34a expression associated with unfavorable prognosis or resistance to chemotherapy. The present study revealed no correlations between these factors; however low
miRNA-34b expression was observed in the group of patients with CD38-positive cells below 30\%. Balatti et al (47) indicated that there is a lower expression level of miRNA-34b/c in patients with CLL with del11q. The present study did not observe such a correlation between deletion in the region of chromosome 11 (where ATM is located) and miRNA-34a expression. This may have been due to the small size of the study group or other molecular phenomena, such as the lack of methylation of the miRNA34b/34c gene cluster, which was observed in CLL (48). It is noteworthy that with high miRNA-34b expression, $>20 \%$ of ZAP-70-positive cells were observed significantly more often. This is notable due to the fact that Fabbri et al (41) demonstrated the existence of the TP-53/miRNA-34b/c/ZAP-70 axis and that TP-53 is a positive regulator of the miRNA-34b/c gene cluster, which has the ability to post-transcriptionally silence TP-53 or ZAP-70 (41). Thus, a relationship between the factors associated with this feedback loop and decreased miRNA-34b expression is expected. The observed high expression of miRNA-34b in the ZAP-70-positive patients in the present study may have been the result of the small size of the study groups, or may have been associated with other molecular mechanisms that interacted with each other.

The situation was similar in present study with miR-29a, whose expression was higher in ZAP-70-positive patients, despite previous evidence of reduced expression of this miRNA in ZAP-70-positive patients (49). Since a high percentage of ZAP-70-positive cells may indicate an aggressive course of CLL, and miRNA-221 is described as an oncomiR, it can be considered as a prognostic marker (23). The present study performed ROC analysis to demonstrate the diagnostic utility of the miRNAs, and revealed that three of them could be useful as prognostic factors; miRNA-181a, miRNA 221 and miRNA-223 could differentiate between patients with low and high risk of progression. There is evidence that miRNA molecules may be a prognostic factor in CLL $(37,38)$.

However, it should be noted that the study group should be expanded in further analyses in order to confirm the present findings. Furthermore, the analysis of a few or a several miRNAs should be performed jointly if the study group is much larger and then a miRNA panel can be proposed. It is now possible to use next-generation sequencing (NGS) as an extensive study to search for miRNA molecules that can serve as prognostic and predictive factors in CLL. Kaur et al (50) conducted a genome-wide small RNA sequencing study to reveal a unique pattern of differential regulation of eight miRNAs in CLL. Upregulated miRNAs include miR-1295a, miR-155 and miR-4524a; while miR-30a, miR-423, miR-486*, let-7e and miR-744 are downregulated (50). This demonstrated that miR-4524a and miR-744 are significantly associated with CLL risk and time to first treatment (50). These authors also validated NGS results using RT-qPCR. Therefore, NGS may be a first-line method in broad analysis to identify miRNAs that may be useful as predictive markers. However, to implement miRNA assessment into practice, a less expensive and more accessible method should be used, such as RT-qPCR.

Beyond research on the diagnostic utility of miRNAs, it is worth noting that these molecules have therapeutic potential. Studies on the expression levels of miRNAs contribute to directing the next steps of research toward specific miRNA molecules that can be used therapeutically as complementary 
antagomirs for silencing miRNA overexpression or as mimic RNAs for supplementing deficiencies of specific molecules. $\mathrm{Fu}$ et al (51) indicated that delivery systems for therapeutic miRNA molecules are different (viral or non-viral vectors or microvesicles). They are used in clinical trials for the application of miRNA-based systems to cancer treatment (52). Examples of miRNA-based agents include: miR-34a (MRX34; Phase I clinical trial, liposome-encapsulated miRNA-34a mimic for the treatment of advanced solid tumors; Clinical trial, NCT01829971) or miRNA-16 (MesomiR-1 Clinical Trials, NCT02369198), a molecule mimicking miR-16 encapsulated in non-viable bacterial minicells with an anti-EGFR bispecific antibody, for the treatment of mesothelioma and non-small cell lung cancer. Research on miRNA expression in different types of cancer, including CLL, is ongoing and are extensive. They are important due to the fact that on their basis miRNA-activity-based therapeutic systems or diagnostic tests can be developed for early cancer detection or disease monitoring.

In conclusion, the present study demonstrated that miRNAs have diagnostic potential. There is a large number of miRNA molecules from which those that are important in particular disease entities or their stages can be selected. The present study demonstrated that among the tested miRNAs, miRNA-181a, miR-221 and miR-223 appeared to have the greatest diagnostic potential in CLL.

\section{Acknowledgements}

The authors would like to thank Mrs. Barbara Kwiatkowska-Drabik and Mrs. Małgorzata Luterek (Department of Cancer Genetics with Cytogenetic Laboratory) for their help during the FISH research.

\section{Funding}

No funding was received.

\section{Availability of data and materials}

The datasets used and/or analyzed during the current study are available from the corresponding author on reasonable request.

\section{Authors' contributions}

AG and AAF conceptualized the study. AG and EWS collected the data. AG performed data analysis. AG, EWS and AAF designed the methodology. AG and AAF confirm the authenticity of all the raw data. AG was project administrator and wrote the original draft. AAF and EWS supervised the present study. All authors have read and approved the final manuscript.

\section{Ethics approval and consent to participate}

Informed consent was obtained from patients and the present study was conducted with the approval of the Ethics Committee of the Medical University of Lublin (approval no. KE-0254/155/2010).

\section{Patient consent for publication}

Not applicable.

\section{Competing interests}

The authors declare that they have no competing interests.

\section{References}

1. Rodriguez A, Griffiths-Jones S, Ashurst JL and Bradley A: Identification of mammalian microRNA host genes and transcription units. Genome Res 14: 1902-1910, 2004.

2. Farazi TA, Spitzer JI, Morozov and Tuschl T: miRNAs in human cancer. J Pathol 223: 102-115, 2011.

3. Lynam-Lennon N, Maher SG and Reynolds JV: The roles of microRNA in cancer and apoptosis. Biol Rev Camb Philos Soc 84: 55-71, 2009.

4. Delgado J and Villamor N: Chronic lymphocytic leukemia in young individuals revisited. Haematologica 99: 4-5, 2014.

5. Bacher U, Kern W, Schoch C, Hiddemann W and Haferlach T: Discrimination of chronic lymphocytic leukemia (CLL) and CLL/PL by cytomorphology can clearly be correlated to specific genetic markers as investigated by interphase fluorescence in situ hybridization (FISH). Ann Hematol 83: 349-355, 2004.

6. Dal Bo M, Rossi FM, Rossi D, Deambrogi C, Bertoni F, Del Giudice I, Palumbo G, Nanni M, Rinaldi A, Kwee I, et al: $13 q 14$ deletion size and number of deleted cells both influence prognosis in chronic lymphocytic leukemia. Genes Chromosomes Cancer 50: 633-643, 2011.

7. Klein U, Lia M, Crespo M, Siegel R, Shen Q, Mo T, Ambesi-Impiombato A, Califano A, Migliazza A, Bhagat G and Dalla-Favera R: The DLEU2/miR-15a/16-1 cluster controls B cell proliferation and its deletion leads to chronic lymphocytic leukemia. Cancer Cell 17: 28-40, 2010.

8. Palamarchuk A, Efanov A, Nazaryan N, Santanam U, Alder H, Rassenti L, Kipps T, Croce CM and Pekarsky Y: 13q14 deletions in CLL involve cooperating tumor suppressors. Blood 115: 3916-3922, 2010.

9. Kiefer Y, Schulte C, Tiemann M and Bullerdiek J: Chronic lymphocytic leukemia-associated chromosomal abnormalities and miRNA deregulation. The Application of Clinical Genetics 5: 21-28, 2012.

10. Austen B, Powell JE, Alvi A, Edwards I, Hooper L, Starczynski J, Taylor AM, Fegan C, Moss P and Stankovic T: Mutations in the ATM gene lead to impaired overall and treatment-free survival that is independent of IGVH mutation status in patients with B-CLL. Blood 106: 3175-3182, 2005.

11. Döhner H, Stilgenbauer S, Benner A, Leupolt E, Kröber A, Bullinger L, Döhner K, Bentz M and Lichter P: Genomic aberrations and survival in chronic lymphocytic leukemia. N Engl J Med 343: 1910-1916, 2000.

12. Döhner H, Stilgenbauer S, James MR, Benner A, Weilguni T, Bentz M, Fischer K, Hunstein W and Lichter P: 11q deletions identify a new subset of B-cell chronic lymphocytic leukemia characterized by extensive nodal involvement and inferior prognosis. Blood 89: 2516-2522, 1997.

13. Marasca R, Maffei R, Martinelli S, Fiorcari S, Bulgarelli J, Debbia G, Rossi D, Rossi FM, Rigolin GM, Martinelli S, et al: Clinical heterogeneity of de novo 11q deletion chronic lymphocytic leukaemia: Prognostic relevance of extent of 11q deleted nuclei inside leukemic clone. Hematol Oncol 31: 88-95, 2013.

14. Matutes E, Oscier D, Garcia-Marco J, Ellis J, Copplestone A, Gillingham R, Hamblin T, Lens D, Swansbury GJ and Catovsky D: Trisomy 12 defines a group of CLL with atypical morphology: Correlation between cytogenetic, clinical and laboratory features in 544 patients. Br J Haematol 92: 382-388, 1996.

15. Zent CS, Kyasa MJ, Evans R and Schichman SA: Chronic lymphocytic leukemia incidence is substantially higher than estimated from tumor registry data. Cancer 92: 1325-1330, 2001.

16. Zenz T, Eichhorst B, Busch R, Denzel T, Häbe S, Winkler D, Bühler A, Edelmann J, Bergmann M, Hopfinger G, et al: TP53 mutation and survival in chronic lymphocytic leukemia. J Clin Oncol 28: 4473-4479, 2010. 
17. Bullrich F, Fujii H, Calin G, Mabuchi H, Negrini M, Pekarsky Y, Rassenti L, Alder H, Reed JC, Keating MJ, et al: Characterization of the 13q14 tumor suppressor locus in CLL: Identification of ALT1, an alternative splice variant of the LEU2 gene. Cancer Res 61: 6640-6648, 2001.

18. Calin GA, Dumitru CD, Shimizu M, Bichi R, Zupo S, Noch E, Aldler H, Rattan S, Keating M, Rai K, et al: Frequent deletions and down-regulation of micro- RNA genes miR15 and miR16 at $13 q 14$ in chronic lymphocytic leukemia. Proc Natl Acad Sci USA 99: 15524-15529, 2002.

19. Pekarsky Y, Santanam U, Cimmino A, Palamarchuk A, Efanov A Maximov V, Volinia S, Alder H, Liu CG, Rassenti L, et al: Tcl1 expression in chronic lymphocytic leukemia is regulated by miR-29 and miR-181. Cancer Res 66: 11590-11593, 2006.

20. Zenz T, Häbe S, Denzel T, Mohr J, Winkler D, Bühler A, Sarno A Groner S, Mertens D, Busch R, et al: Detailed analysis of p53 pathway defects in fludarabine-refractory chronic lymphocytic leukemia (CLL): Dissecting the contribution of $17 \mathrm{p}$ deletion, TP53 mutation, p53-p21 dysfunction, and miR34a in a prospective clinical trial. Blood 114: 2589-2597, 2009.

21. Calin GA, Liu CG, Sevignani C, Ferracin M, Felli N, Dumitru CD, Shimizu M, Cimmino A, Zupo S, Dono M, et al: MicroRNA profiling reveals distinct signaturesin B cell chronic lymphocytic leukemias. Proc Natl Acad Sci USA 101: 11755-11760, 2004

22. Sandhu SK, Volinia S, Costinean S, Galasso M, Neinast R, Santhanam R, Parthun MR, Perrotti D, Marcucci G, Garzon R and Croce CM: miR-155 targets histone deacetylase 4 (HDAC4) and impairs transcriptional activity of B-cell lymphoma 6 (BCL6) in the E $\mu$-miR-155 transgenic mouse model. Proc Natl Acad Sci USA 109: 20047-2052, 2012.

23. Frenquelli M, Muzio M, Scielzo C, Fazi C, Scarfò L, Rossi C, Ferrari G, Ghia P and Caligaris-Cappio F: MicroRNA and proliferation control in chronic lymphocytic leukemia: Functional relationship between miR-221/222 cluster and p27. Blood 115: 3949-3959, 2010

24. Montillo M, Hamblin T, Hallek M, Montserrat E and Morra E: Chronic lymphocytic leukemia: Novel prognostic factors and their relevance for risk-adapted therapeutic strategies. Haematologica 90: 391-399, 2005.

25. Hallek M, Cheson BD, Catovsky D, Caligaris-Cappio F, Dighiero G, Döhner H, Hillmen P, Keating MJ, Montserrat E, Rai KR, et al: Guidelines for the diagnosis and treatment of chronic lymphocytic leukemia: A report from the International Workshop on Chronic Lymphocytic Leukemia updating the National Cancer Institute-Working Group 1996 guidelines. Blood 111: 5446-5456, 2008.

26. Livak KJ and Schmittgen TD: Analysis of relative gene expression data using real-time quantitative PCR and the 2(-Delta Delta C(T)) method. Methods 25: 402-408, 2001.

27. Mato A, Nabhan C, Kay NE, Lamanna N, Kipps TJ, Grinblatt DL, Flowers CR, Farber CM, Davids MS Kiselev P, et al: Prognostic Testing patterns and outcomes of chronic lymphocytic leukemia patients stratified by fluorescence in situ hybridization/cytogenetics: A real-world clinical experience in the connect CLL registry. Clin Lymphoma Myeloma Leuk 18: 114-124.e2, 2018.

28. Hallek M, Cheson BD, Catovsky D, Caligaris-Cappio F, Dighiero G, Döhner H, Hillmen P, Keating M, Montserrat E, Chiorazzi N, et al: iwCLL guidelines for diagnosis, indications for treatment, response assessment, and supportive management of CLL. Blood 131: 2745-2760, 2018.

29. Eichhorst B, Robak T, Montserrat E, Ghia P, Niemann CU, Kater AP, Gregor M, Cymbalista F, Buske C, Hillmen P, et al: Chronic lymphocytic leukaemia: ESMO Clinical Practice Guidelines for diagnosis, treatment and follow-up. Ann Oncol 32: 23-33, 2021

30. Baliakas P, Jeromin S, Iskas M, Puiggros A, Plevova K, Nguyen-Khac F, Davis Z, Rigolin GM, Visentin A, Xochelli A, et al: Cytogenetic complexity in chronic lymphocytic leukemia: Definitions, associations, and clinical impact. Blood 133: 1205-1216, 2019

31. Galka-Marciniak P, Urbanek-Trzeciak MO, Nawrocka PM, Dutkiewicz A, Giefing M, Lewandowska MA and Kozlowski P: Somatic mutations in miRNA genes in lung cancer-potential functional consequences of non-coding sequence variants. Cancers (Basel) 11: 793, 2019.

32. Gao Y, Lin L, Li T, Yang J and Wei Y: The role of miRNA-223 in cancer: Function, diagnosis and therapy. Gene 616: 1-7, 2017.
33. Luo P, Wang Q, Ye Y, Zhang J, Lu D, Cheng L, Zhou H, Xie M and Wang B: miR-223-3p functions as a tumor suppressor in lung squamous cell carcinoma by miR-223-3p-mutant p53 regulatory feedback loop. J Exp Clin Cancer Res 38: 74, 2019.

34. Humplikova L, Kollinerova S, Papajik T, Pikalova Z, Holzerova M, Prochazka V, Divoka M, Modriansky M, Indrak K and Jarosova M: Expression of miR-15a and miR-16-1 in patients with chronic lymphocytic leukemia. Biomed Pap Med Fac Univ Palacky Olomouc Czech Repub 157: 284-293, 2013.

35. Rossi M, Fuligni F, Ciccone M, Agostinelli C, Righi S, Luciani M, Laginestra MA, Rigolin GM, Sapienza MR, Gazzola A, et al: Hsa-miR-15a and Hsa-miR-16-1 expression is not related to proliferation centers abundance and other prognostic factors in chronic lymphocytic leukemia. Biomed Res Int 2013: 715391, 2013.

36. Zhu DX, Zhu W, Fang C, Fan L, Zou ZJ, Wang YH, Liu P, Hong M, Miao KR, Liu P, et al: miR-181a/b significantly enhances drug sensitivity in chronic lymphocytic leukemia cells via targeting multiple anti-apoptosis genes. Carcinogenesis 33: 1294-1301, 2012.

37. Visone R, Veronese A, Balatti V and Croce CM: miR-181b: New perspective to evaluate disease progression in chronic lymphocytic leukemia. Oncotarget 3: 195-202, 2012.

38. Visone R, Veronese A, Rassenti LZ, Balatti V, Pearl DK, Acunzo M, Volinia S, Taccioli C, Kipps TJ and Croce CM: miR-181b is a biomarker of disease progression in chronic lymphocytic leukemia. Blood 118: 3072-3079, 2011.

39. Zhou K, Yi S, Yu Z, Li Z, Wang Y, Zou D, Qi J, Zhao Y and Qiu L: MicroRNA-223 expression is uniformly down-regulated in B cell lymphoproliferative disorders and is associated with poor survival in patients with chronic lymphocytic leukemia. Leuk Lymphoma 53 $1155-1161,2012$

40. Yang L, Zhao W, Wei P, Zuo W and Zhu S: Tumor suppressor p53 induces miR-15a processing to inhibit neuronal apoptosis inhibitory protein (NAIP) in the apoptotic response DNA damage in breast cancer cell. Am J Transl Res 9: 683-691, 2017.

41. Fabbri M, Bottoni A, Shimizu M, Spizzo R, Nicoloso MS, Rossi S, Barbarotto E, Cimmino A, Adair B, Wojcik SE, et al: Association of a microRNA/TP53 feedback circuitry with pathogenesis and outcome of B-cell chronic lymphocytic leukemia. JAMA 305: 59-67, 2011

42. Liu J, Chen G, Feng L, Zhang W, Pelicano H, Wang F Ogasawara MA, Lu W, Amin HM, Croce CM, et al: Loss of p53 and altered miR15-a/16-1 MCL-1 pathway in CLL: Insights from TCL1-Tg:p53(-/-) mouse model and primary human leukemia cells. Leukemia 28: 118-128, 2014.

43. Janaki RM: Functions and epigenetic aspects of miR-15/16: Possible future cancer therapeutics. Gene Reports 12: 149-164, 2018.

44. Pekarsky Y and Croce CM: Is miR-29 an oncogene or tumor suppressor in CLL? Oncotarget 1: 224-227, 2010.

45. Mraz M, Malinova K, Kotaskova J, Pavlova S, Tichy B, Malcikova J, Stano Kozubik K, Smardova J, Brychtova Y, Doubek M, et al: miR-34a, miR-29c and miR-17-5p are downregulated in CLL patients with TP53 abnormalities. Leukemia 23: 1159-1163, 2009.

46. Zhang L, Liao Y and Tang L: MicroRNA-34 family: a potential tumor suppressor and therapeutic candidate in cancer. J Exp Clin Cancer Res 38: 53, 2019.

47. Balatti V, Pekarky Y, Rizzotto L and Croce CM: miR deregulation in CLL. Advances in experimental medicine and biology 792: 309-325, 2013.

48. Deneberg S, Kanduri M, Ali D, Bengtzen S, Karimi M, Qu Y, Kimby E, Mansouri L, Rosenquist R,Lennartsson A and Lehmann S microRNA-34b/c on chromosome 11q23 is aberrantly methylated in chronic lymphocytic leukemia. Epigenetics 9: 910-917, 2014.

49. Farahat NMG, Elkaffash DMNED, Alghandour AH, Swelem RS and Abo El-Wafa RAH: Study of microRNA profile as a molecular biomarker in Egyptian Chronic Lymphocytic Leukemia. Indian J Hematol Blood Transfus 35: 89-99, 2019.

50. Kaur G, Ruhela V, Rani L, Gupta A, Sriram K, Gogia A, Sharma A, Kumar L and Gupta R. RNA-Seq profiling of deregulated miRs in CLL and their impact on clinical outcome. Blood Cancer J 10: 6, 2020.

51. Fu Y, Chen J and Huang Z: Recent progress in microRNA-based delivery systems for the treatment of human disease. ExRNA 1: 24, 2019.

52. Chakraborty C, Sharma AR, Sharma G and Lee SS: Therapeutic advances of miRNAs: A preclinical and clinical update. J Adv Res 28: 127-138, 2020 .

This work is licensed under a Creative Commons Attribution-NonCommercial-NoDerivatives 4.0 International (CC BY-NC-ND 4.0) License. 